\title{
SULFONATED PHTHALIMIDOMETHYL ALUMINUM PHTHALOCYANINE: THE EFFECT OF HYDROPHOBIC SUBSTITUENTS ON THE in vitro PHOTOTOXICITY OF PHTHALOCYANINES
}

\author{
Benoit Paquette ${ }^{1}$, Ross W. Boyle ${ }^{1}$, Hasrat Ali ${ }^{1}$, Alexander H. Maclennan ${ }^{2}$, \\ T. George TruscotT ${ }^{2}$ and Johan E. van LieR ${ }^{1 *}$ \\ ' MRC Group in the Radiation Sciences, Faculty of Medicine, University of Sherbrooke, \\ Sherbrooke, Québec, Canada J1H 5N4 and ${ }^{2}$ Department of Chemistry, Paisley College of \\ Technology, High St., Paisley, Strathclyde PA1 2BE, UK
}

(Received 9 May 1990; accepted 12 September 1990)

\begin{abstract}
The photocytotoxicity of sulfonated phthalimidomethyl aluminum phthalocyanine, a more hydrophobic photosensitizer as compared to phthalocyanine substituted with sulfonate groups only, was investigated. Inclusion of 1-2 phthalimidomethyl groups into disulfonated aluminum phthalocyanine, resulted in increased partition coefficients between $n$-octanol and water, and a six-fold increase in both cellular uptake and photocytotoxicity towards Chinese hamster lung fibroblast cells (line V-79). Reducing the number of phthalimidomethyl groups, or increasing the degree of sulfonation, lead to a decrease in the partition coefficient, cellular uptake, and phototoxicity. The quantum yield of singlet oxygen was comparable for all dyes tested in this series, indicating that no significant change in this photophysical parameter resulted from phthalimidomethylation. These results suggest that the addition of 1-2 phthalimidomethyl groups to disulfonated aluminum phthalocyanine improves cellular uptake, but, as the relative efficiency of cell killing was not effected, the intracellular distribution on photosensitive molecules may not be modified.
\end{abstract}

\section{INTRODUCTION}

Photodynamic therapy (PDT) $\dagger$ has been proposed as an alternative therapy of neoplastic disease (Dougherty et al., 1978) and due to the advantageous relationship between the absorption maximum and light penetration in tissue, the phthalocyanines are studied as potential photosensitizers for use in this treatment (for recent reviews see Rosenthal and Ben-Hur, 1989; van Lier and Spikes, 1989; van Lier, 1990). These well-defined compounds, when sulfonated to render them water soluble, and chelated with an appropriate metal in order to maximize generation of the reactive species singlet oxygen (Girotti, 1983: Langlois et al., 1986) efficiently destroyed transformed cells (Brasseur et al., 1985, 1987; Ben-Hur and Rosenthal, 1985; Chan et al., 1986). Using V-79 Chinese hamster cells, amphiphilic phthalocyanines with two sulfonate groups on adjacent benzenoid rings interacted with the lipid portion of the plasma membrane and were shown to enter into the cytoplasm after $24 \mathrm{~h}$ incubation in vitro (Paquette et al., 1988). This amphiphilic property explained their high photocytotoxicity under in vitro conditions.

In vivo, using Photofrin II or phthalocyanines,

\footnotetext{
* To whom correspondence should be addressed.

† Abbreviations: AlOH-PcS, sulfonated aluminum phthalocyanine; AlOH-PcSP, sulfonated phthalimidomethyl aluminum phthalocyanine; LDL, low density lipoprotein; PBS, phosphate-buffered saline; PDT, photodynamic therapy; $\phi_{\Delta}$, quantum vield of singlet oxygen.
}

necrosis mainly results from tumor microcirculation stasis (Fingar and Henderson, 1987; Selman et al., 1985; Reed et al., 1989). Such an indirect effect on the tumor could allow tumor regrowth unless normal blood vessels surrounding the tumor were also destroyed (Star et al., 1986). The effect also appeared to be non-specific as both normal and tumoral vessels were damaged to a similar degree (Reed et al., 1989). Among the sulfonated aluminum phthalocyanines (AlOH-PcS) the lower sulfonated amphiphilic dyes have a superior potential for direct tumor cell inactivation while being relatively sparing to the vasculature (Henderson and Bellnier, 1989).

With the aim of augmenting direct tumor response on neoplastic cells, we synthesized a more hydrophobic sulfonated aluminum phthalocyanine by introducing phthalimidomethyl groups concurrently at the sulfonation stage (Fig. 1). In this study we report the partition coefficient, cellular uptake, photocytotoxicity, and quantum yield of single oxygen for sulfonated phthalimidomethyl aluminum phthalocyanine (AlOH-PcSP), and compare these results with those obtained for unmodified $\mathrm{AlOH}$ PcS.

\section{MATERIALS AND METHODS}

Synthesis. Sulfonated aluminum phthalocyanine was prepared as previously described (Ali et al., 1988). Sulfonated phthalimidomethyl aluminum phthalocyanine was prepared as follows: $1.34 \mathrm{~g}(2.32 \mathrm{mmol})$ of aluminum phthalocyanine (Ciba Geigy) was added to $5 \mathrm{~mL}$ of concentrated sulfuric acid, the mixture was stirred for $20 \mathrm{~min}$ 


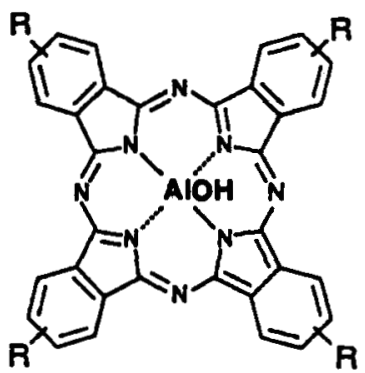

$$
\mathrm{R}=\mathrm{H} \text { or } \mathrm{SO}_{3}^{-} \text {or }
$$

Figure 1. Chemical structure of sulfonated phthalimidomethyl aluminum phthalocyanines (AlOH-PcSP). $R=H$, $\mathrm{SO}_{3}^{-}$or $\mathrm{CH}_{2}$-phthalimide, depending on the degree of substitution and sulfonation.

then $0.41 \mathrm{~g}$ (2.79 mmol) phthalimide, $0.12 \mathrm{~g}$ (4 mmol) par. aformaldehyde, and $15 \mathrm{~mL}$ of oleum containing $30 \%$ free $\mathrm{SO}_{3}$ were added. The mixture was stirred at $80^{\circ} \mathrm{C}$ for $5 \mathrm{~h}$. The reaction mixture was poured on crushed ice $(200 \mathrm{~mL})$ and the resulting precipitate recovered by filtration, washed with $1 M \mathrm{H}_{2} \mathrm{SO}_{4}(200 \mathrm{~mL})$, redissolved in $1 M$ $\mathrm{KOH}$ and filtered again before being neutralized. After removal of water by evaporation in vacuo, salt was removed from the dried product by dissolution in dry methanol and filtration to yield AlOH-PcSP $(1.67 \mathrm{~g})$. Molar absorption coefficients of the AlOH-PcSP ( $\mathrm{E}_{\mathrm{McOH}}$ $=1.5 \times 10^{5}$ at $\lambda_{\max }=676 \mathrm{~nm}$ ) were slightly lower than those found for the AlOH-PcS $\left(\epsilon_{\mathrm{MeOH}}=1.9 \times 10^{5}\right.$ at $\lambda_{\max }$ $=674 \mathrm{~nm}$ ).

Fractionation of sulfonated phthalimidomethyl aluminum phthalocyanine (AlOH-PCSP). "Crude" AlOH-PcSP (1.1 g) was fractionated by preparative medium pressure reverse phase chromatography on a $30 \mathrm{~cm}$ long by $2 \mathrm{~cm}$ ID glass column packed with $\mathrm{C}-18$ reverse phase, particle size 25-40 $\mu \mathrm{m}$ (Macherey-Nagel, Düren, Germany) using a linear gradient from 0 to $95 \% \mathrm{MeOH}$ in $10 \mathrm{mM}$ sodium phosphate buffer, pH 5 (Ali et al., 1988). Samples were analyzed by reverse phase HPLC, eluting phthalocyanines being detected spectroscopically at $670 \mathrm{~nm}$, and pooled to yield six main fractions (A-F). The relative level of substitution was determined by oxidative degradation of $1 \mathrm{mg}$ of compound using cerium ammonium nitrate $(0.01$ mmol; $4-5 \mathrm{~mL}$ ) in hot, acidic aqueous solution, followed by reverse phase HPLC analysis (Ali et al., 1988). The eluting phthalimide, and substituted phthalimide units, resulting from the oxidation, were detected spectroscopically at $215 \mathrm{~nm}$. The identity of phthalimide degradation products was determined by coupled HPLC/mass spectrometry. Unsulfonated material (phthalimide $R_{\mathrm{t}}=$ $29 \mathrm{~min}$; phthalimidomethylphthalimide $R_{\mathrm{t}}=35 \mathrm{~min}$ ) was characterized by direct comparison of chromatographic properties with those of authentic samples, whereas the sulfonated moieties were found indirectly by HPLC comparison of $\mathrm{AICl}-\mathrm{PcP}$ and AIOH-PcSP degradation fragments (sulfophthalimide $R_{\mathrm{t}}=16 \mathrm{~min}$; sulfophthalimidomethylphthalimide $R_{\mathrm{t}}=20 \mathrm{~min}$ ). Under the reaction conditions some sulfonation of the benzenoid ring of the phthalimidomethyl group also resulted. The level of this sulfophthalimidomethyl moiety in each fraction was found to be constant with a relative value of $0.2 \mathrm{~mol}$ per mol Pc which was taken into account as sulfonate substitution in the molar composition of the various frac- tions. In this manner the following compositions were assigned to fractions $A-F$ : $A\left(R_{1}=18 \mathrm{~min}\right), A l O H$ $\mathrm{PcS}_{3.7} \mathrm{P}_{0.1} ; \mathrm{B}\left(R_{\mathrm{t}}=20 \mathrm{~min}\right), \mathrm{AlOH}-\mathrm{PcS}_{3.2} \mathrm{P}_{0.2} ; \mathrm{C}\left(R_{\mathrm{t}}=\right.$ $25 \mathrm{~min})$, AlOH-PcS ${ }_{3.0} \mathrm{P}_{0.3} ; \mathrm{D}\left(R_{\mathrm{t}}=28-33 \mathrm{~min}\right)$, AlOH$\mathrm{PcS}_{3.2} \mathrm{P}_{0.4} ;$ E $\left(R_{\mathrm{t}}=37 \mathrm{~min}\right), \quad \mathrm{AlOH}-\mathrm{PcS}_{2.6} \mathrm{P}_{0.6} ; \mathrm{F}$ $\left(R_{\mathrm{t}}=40 \mathrm{~min}\right)$, AlOH-PcS $2.4 \mathrm{P}_{1.2}$. For the in vitro studies only fractions $D$ and $F$ were evaluated.

Partitioning studies. Dyes (25-300 $\mathrm{n} M)$ were partitioned between $n$-octanol and $100 \mathrm{~m} M$ Tris buffer $\mathrm{pH}$ 7.4. After shaking for $2 \mathrm{~min}$, the phases were separated by centrifugation. The dye concentration in each phase was measured by fluorescence, after 40 -fold dilution in $100 \%$ methanol, using a SLM-Aminco SPF-500C spectrofluorometer (AlOH-PcS: $\lambda_{\mathrm{cx}}=664 \mathrm{~nm}, \lambda_{\mathrm{cm}}=684 \mathrm{~nm}$; AlOH-PcSP: $\lambda_{\mathrm{cx}}=666 \mathrm{~nm}, \lambda_{\mathrm{cm}}=686 \mathrm{~nm}$ ).

Cell uptake. $3 \times 10^{6}$ Chinese hamster lung fibroblasts cells (line V-79) were plated in $60 \mathrm{~mm}$ Petri dishes. After an incubation period of $3 \mathrm{~h}$ under $5 \% \mathrm{CO}_{2}$, to allow cell attachment, $10 \mu \mathrm{M}$ dye in medium ( $1 \mathrm{~mL}$ ) containing $1 \%$ serum was added and the cells were incubated for $1 \mathrm{~h}$. Absorbed dyes were extracted and quantified as previously described (Paquette et al., 1990). Briefly, after removal of the medium, cells were washed three times with PBS and detached with $600 \mu \mathrm{L}$ trypsin-EDTA $0.25 \%$ (4-5 min incubation) and dishes were washed with $600 \mu \mathrm{L}$ PBS. Cells were collected by centrifugation in $1.5 \mathrm{~mL}$ plastic tubes $(5 \mathrm{~min}, 600 \mathrm{~g})$ and resuspended in $200 \mu \mathrm{L}$ of buffer (Tris $0.2 M, \mathrm{MgCl}_{2} 10 \mathrm{~m} M, \mathrm{CaCl}_{2} 1 \mathrm{mM}, \mathrm{pH} 7.8$ ). After three freeze-thaw cycles in liquid nitrogen, cell debris was incubated in the dark, overnight, with $0.5 \mathrm{~A}_{280}$ unit of proteinase $\mathbf{K}$ (Sigma Chemical Co, St. Louis, MO) and diluted in $100 \mu \mathrm{L}$ of Tris buffer. DNA was digested for $2 \mathrm{~h}$ at $37^{\circ} \mathrm{C}$ with $1 \mathrm{~A}_{280}$ unit of micrococcal nuclease (Worthington, Freehold, NJ). To eliminate hydrophobic and ionic interactions with cellular fragments, $50 \mu \mathrm{L}$ DMF was added, whereafter the mixture was incubated for 30 min followed by the addition of $50 \mu \mathrm{L}$ of $1.0 \mathrm{~N} \mathrm{NaOH}$ and a $10 \mathrm{~min}$ incubation period at $37^{\circ} \mathrm{C}$. After 40 -fold dilution in $100 \%$ methanol, dye concentrations were measured by fluorescence as described above.

Photocytotoxicity assay. Cell survival of Chinese hamster lung fibroblasts (line V-79) was determined using a colony forming assay as described by Brasseur et al. (1985). After the attachment of 200 cells in Petri dishes, the cells were rinsed with PBS, and incubated for $1 \mathrm{~h}$ with $1 \mathrm{~mL}$ of medium containing $1 \%$ serum and the dye. After removal of the dye and washing with PBS, the cells were exposed at room temperature for $4 \mathrm{~min}$ to red light. The irradiation device consisted of a $500 \mathrm{~W}$ tungsten/halogen lamp equipped with a $10 \mathrm{~cm}$ water filter and a red filter (264390, Ealing). From the emission spectrum monitored with a monochromator (Instruments S.A., Inc., Jobin Yvon Division, Metuchen, NJ) the fluence rate over the absorption peak of the photoactive monomeric dye $\left(\lambda_{\max } \pm 20 \mathrm{~nm}\right)$ was calculated and set at $100 \mathrm{~W} / \mathrm{m}^{2}$ for a final dose of $24 \mathrm{~kJ} / \mathrm{m}^{2}$. Experiments were repeated three times using three dishes per concentration point.

Quantum yield of singlet oxygen. Singlet oxygen quantum yields were determined for the fractionated product and $\mathrm{AlOH}-\mathrm{PcS}_{4}$ (Porphyrin Products) in deuterated methanol using the infrared luminescence technique (Rodgers and Snowden, 1982). Excitation of the soluton was by a $Q$ switched, frequency doubled ruby laser $(347 \mathrm{~nm})$. Hematoporphyrin hydrochloride (Porphyrin Products) was used as standard, the absolute singlet oxygen quantum yield for this compound having been determined previously by the time resolved thermal lensing technique (Redmond and Braslavsky, 1988).

\section{RESULTS}

Partition coefficient data (Table 1) show that decreasing the number of sulfonate groups and 
Table 1. Properties of differently substituted AlOH-PcSP and AlOH-PcS

\begin{tabular}{|c|c|c|c|c|c|}
\hline Photosensitizer & $\begin{array}{l}\text { Partition } \\
\text { coefficient }^{*} \\
( \pm \text { SD })\end{array}$ & $\begin{array}{l}\text { Quantum } \\
\text { yield of } \\
\text { singlet } \\
\text { oxygent }\end{array}$ & $\begin{array}{c}\text { Cellular uptake } \\
(\mu M)( \pm \mathrm{SD})\end{array}$ & $\begin{array}{c}L_{9_{0}} \\
\text { extracelluiar } \$ \\
(\mu M)\end{array}$ & $\begin{array}{l}\text { Relative } \\
\text { quantum } \\
\text { efficiency of } \\
\text { cell killing }\end{array}$ \\
\hline AlOH-PcS $3.7 P_{0.1}$ & $<0.01$ & 0.35 & $1.6(0.2)$ & $>50$ & - \\
\hline $\mathrm{AlOH}-\mathrm{PcS}_{3.2} \mathrm{P}_{0,4}$ & $0.19(0.01)$ & 0.38 & $31.0(1.3)$ & 0.96 & 0.86 \\
\hline AlOH-PcS ${ }_{2.4} P_{1.2}$ & $1.12(0.08)$ & 0.36 & $82.4(8.2)$ & 0.28 & 1.09 \\
\hline $\mathrm{AlOH}-\mathrm{PeS}_{4}$ & $<0.01$ & 0.36 & - & $>50$ & - \\
\hline $\mathrm{AlOH} \cdot \mathrm{PcS}_{2}$ & $0.44(0.03)$ & - & $14.9(1.7)$ & 1.7 & 1.0 \\
\hline
\end{tabular}

*Dyes (25-300 $\mathrm{n} M$ ) were partitioned between $n$-octanol and $100 \mathrm{~m} M$ Tris buffer pH 7.4.

†Quantum yields of singlet oxygen were obtained relative to hematoporphyrin dihydrochloride $\left(\phi_{\Delta}=0.64\right)$ using the IR luminescence technique.

$\ddagger$ Cellular uptake was measured after incubating Chinese hamster cells (V-79) with $10 \mu M$ of dyes in $1 \%$ serum media during $1 \mathrm{~h}$.

§The extracellular $\mathrm{LD}_{90}$ against V-79 cells were calculated from the survival curves presented in Fig. 2.

|The relative quantum efficiency of cell killing was calculated from the LD 90 corrected for the amount of dye in the cells, taking the value for $\mathrm{AlOH} \cdot \mathrm{PcS}_{2}$ as unity.

increasing the number of phthalimidomethyl substituents increase the hydrophobicity of the dyes. Selecting the most hydrophobic of the water soluble AlOH-PcSP fractions, i.e. fraction $F$ which contained an average of 2.4 sulfonate and 1.2 phthalimidomethyl groups per Pc molecule (AlOH$\mathrm{PcS}_{2.4} \mathrm{P}_{1.2}$ ), we find that the effect of incorporation of the phthalimidomethyl group results in an increase of the partition coefficient by 2.6 times.

Comparing data for cellular uptake with partition coefficients (Table 1), a relationship between hydrophobicity and cell uptake is observed. Higher hydrophobicity of dyes correlates well with an improved cellular uptake of 60 times between AlOH$\mathrm{PcS}_{3.7} \mathrm{P}_{0.1}$ and $\mathrm{AlOH}-\mathrm{PcS}_{2.4} \mathrm{P}_{1.2}$. The isolated effect of phthalimidomethyl addition on disulfonated dyes can be seen from the 5.6 times higher cellular uptake of $\mathrm{AlOH}-\mathrm{PcS}_{2.4} \mathrm{P}_{1.2}$ as compared to $\mathrm{AlOH}-\mathrm{PcS}_{2}$. Fraction D, i.e. $\mathrm{AlOH}-\mathrm{PcS}_{3.2} \mathrm{P}_{0.4}$, was the only one which did not follow the hydrophobicity-cellular uptake relationship. The three sulfonate groups contributed to partitioning the dye more in the aqueous phase while the addition of an average of 0.4 phthalimidomethyl allowed a cellular uptake 2.1 times higher than the amphiphilic $\mathrm{AlOH}-\mathrm{PcS}_{2}$. This increase in cellular uptake corresponds with an increase in photocytotoxicity of the dyes in vitro (Fig. 2). AlOH- $\mathrm{PcS}_{3.2} \mathrm{P}_{0.4}$ and $\mathrm{AlOH}-\mathrm{PcS}_{2.4} \mathrm{P}_{1.2}$ exhibited $\mathrm{LD}_{90}$ values (extracellular) of 0.96 and $0.28 \mu M$ respectively, while $\mathrm{AlOH}-\mathrm{PcS}_{3.7} \mathrm{P}_{0.1}$ failed to achieve $90 \%$ cell mortality even at the highest concentrations used $(50 \mu M)$. The influence of the phthalimidomethyl group on photocytotoxicity was clearly indicated by comparing $\mathrm{AlOH}-\mathrm{PcS}_{2.4} \mathbf{P}_{1.2}$ with $\mathrm{AlOH}-\mathrm{PcS}_{2}$ where inclusion of the phthalimidomethyl moiety resulted in an increased photodynamic potency of more than 6-fold $\left(\mathrm{AlOH}-\mathrm{PcS}_{2}\right.$, $\mathrm{LD}_{90}=1.7 \mu M$; Paquette et al., 1988). The differing phototoxic effects do not relate to the efficiency of singlet oxygen production for the

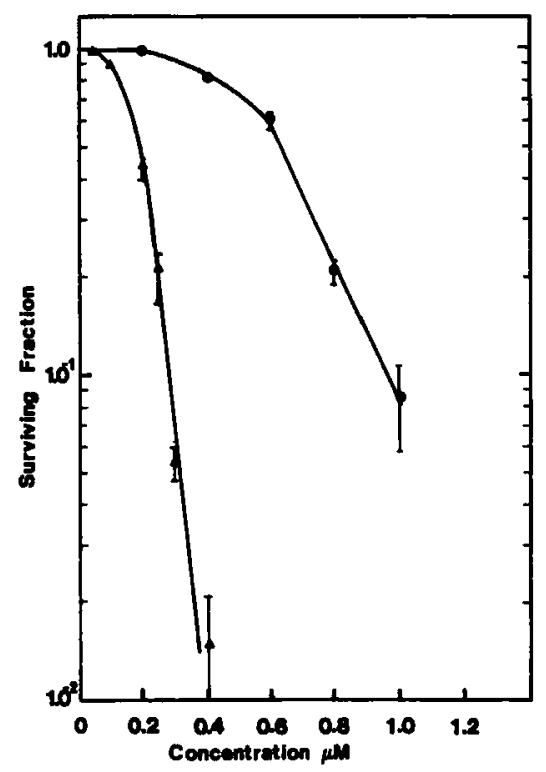

Figure 2. Survival of V-79 cells incubated for $1 \mathrm{~h}$ at $37^{\circ} \mathrm{C}$ with $\mathrm{AlOH}-\mathrm{PcS}_{3.2} \mathrm{P}_{0.4}(\mathrm{O})$ and $\mathrm{AlOH}-\mathrm{PcS}_{2.4} \mathrm{P}_{1.2}(\Delta)$ followed by exposure to red light. Experiments were repeated three times using three dishes per concentration points.

monomerized fractions of the various AlOH-PcSP in homogeneous solution, since all the dye preparations gave similar quantum yields (Table 1 ). The effect of inclusion of phthalimidomethyl groups in AlOH-PcS did correlate very well with the relative quantum efficiency of cell killing of the various dye preparations (Table 1). After expressing phototoxicity as a function of cellular uptake, AlOH-PcS and $\mathrm{AlOH}-\mathrm{PcS}_{2.4} \mathrm{P}_{1.2}$ exhibited the same relative efficiency, while $\mathrm{AlOH}-\mathrm{PcS}_{3.2} \mathrm{P}_{0.4}$ was only $14 \%$ less phototoxic.

\section{DISCUSSION}

These results show clearly that the higher cellular uptake of differently substituted AlOH-PcSP in 
vitro is associated with the more hydrophobic derivatives of sulfonated phthalocyanines. Comparing dye fractions $\mathrm{AlOH}-\mathrm{PcS}_{2.4} \mathrm{P}_{1.2}$ and $\mathrm{AlOH}-\mathrm{PcS}_{2}$, the fraction substituted with phthalimidomethyl groups partitioned more in the $n$-octanol phase, and exhibited both increased cellular uptake and photocytotoxicity by about a factor of six without showing significant differences in the quantum yield of singlet oxygen. Thus, the strategy of limiting the degree of sulfonation to obtain an amphiphilic photosensitizer, whilst increasing the number of phthalimidomethyl substituents to increase hydrophobicity, and hence membrane penetration, results in an increased photodynamic effect.

It has been reported that amphiphilic dyes interact with the lipid portion of plasma membranes (Chatelier et al., 1985), thereby facilitating transport of these molecules into the cell (Paquette et al., 1988). This same amphiphilic property allows more efficient binding to low density lipoprotein (LDL), which has been implicated in the transport of porphyrin based sensitizers to tumorous tissue (Kessel et al., 1987). Tetraphenylporphine monosulfonate, and the more hydrophobic of the disulfonated isomers bound to a greater extent with $\mathrm{LDL}$, and were preferentially localized in neoplastic cells. In contrast, the tetra-, tri- and less hydrophobic disulfonated isomer were associated more with the albumin fraction of the serum proteins and distributed mainly in the stroma of the tumor. Although little additional data has been published to corroborate these results, with regard to phthalocyanines, it might be expected on the basis of sensitizer structure, that both tetraphenylporphine and Pc's, with the same degree of sulfonation, would exhibit similar affinities for the different serum lipoproteins and thence be distributed in a like manner. Thus the probability of a direct tumor response should be greater if the hydrophobicity of the molecule is increased whilst retaining water solubility.

Addition of hydrophobic phthalimidomethyl groups to AlOH-PcS results in a dramatic increase in cell uptake. A one hour incubation period of $\mathrm{V}$ 79 cells with $10 \mu M$ Al-OH-PcS ${ }_{2.4} \mathrm{P}_{1.2}$ did result in an 8-fold higher intracellular as compared to extracellular, dye concentration (Table 1). The phthalimidomethyl group did not however, appear to modify the intracellular distribution of the dye as the relative quantum efficiency of cell killing of $\mathrm{AlOH}-\mathrm{PcS}_{2.4} \mathrm{P}_{1,2}$ and $\mathrm{AlOH}-\mathrm{PcS}_{2}$ were similar.

Kessel (1986) and Moan et al. (1983) have reported that plasma membrane is an important target following in vitro PDT. This assumption on the nature of the intracellular target is supported by a correlation between plasma membrane damage and loss of cell viability after a short incubation period with $\mathrm{HpD}$. Our results with both $\mathrm{AlOH}$ $\mathrm{PcS}_{2.4} \mathrm{P}_{1.2}$ and $\mathrm{AlOH}-\mathrm{PcS}_{3.2} \mathrm{P}_{0.4}$ were consistent with this assumption. A more hydrophobic amphiphilic dye, such as $\mathrm{AlOH}-\mathrm{PcS}_{2.4} \mathrm{P}_{1.2}$, should interact with the lipid portion of plasma membrane (Chatelier $e t$ al., 1985). It therefore seems logical to obtain a higher membrane interaction, and thus optimal cell uptake, by increasing the hydrophobicity of an amphiphilic dye. In the case of AlOH-PcS ${ }_{3.2} P_{0.4}$ the relative yield of cell killing was only $14 \%$ lower than that observed for AlOH-PcS ${ }_{2}$. This result seemed surprising, since it has been previously established that phthalocyanines substituted with three sulfonate groups interact poorly in vitro with the plasma membrane of V-79 cells, resulting, even after $24 \mathrm{~h}$ incubation, in little cell uptake and photocytotoxicity (Brasseur et al., 1987; Paquette et al., 1988). The relatively low partition coefficient of AlOH-PcS ${ }_{3.2} \mathrm{P}_{0.4}$, as compared to the amphiphilic $\mathrm{AlOH}-\mathrm{PcS}_{2}$, also suggests a weak interaction with the membrane, however, both the cellular uptake and phototoxic effect were improved. Thus, these results indicate that the addition of phthalimidomethyl groups on $\mathrm{AlOH}-\mathrm{PcS}_{3.2} \mathrm{P}_{0.4}$ compensates for the adverse hydrophilic effect of the sulfonate substituents, and induces phototoxicity by permitting interaction with the plasma membrane, subsequently mediating photoinduced damage to the tumor cell.

In summary, these in vitro data with V-79 cells confirm the correlation between hydrophobicity, cellular uptake and cell killing of the photosensitizer, and demonstrate the relevance of introducing phthalimidomethyl groups into amphiphilic sulfonated phthalocyanines to improve cellular uptake and photodynamic action. The involvement of this correlation, with regard to both serum distribution of dye and tumor response in vivo, is currently being investigated in our laboratory.

Acknowledgements-This work was supported by the Medical Research Council of Canada. R. W. B. thanks the C. K. Marr Educational Trust for a scholarship. The authors thank Dr. C. Campbell and Professor I. MacPherson for considerable advice on Pc synthesis and Miss Huguette Savoie for expert technical assistance.

\section{REFERENCES}

Ali, H., R. Langlois, J. R. Wagner, N. Brasseur, B. Paquette and J. E. van Lier (1988) Biological activities of phthalocyanines - X. Syntheses and analyses of sulfonated phthalocyanines. Photochem. Photobiol. 44, 117-123.

Ben-Hur, E. and I. Rosenthal (1985) Photosensitized inactivation of Chinese hamster cells by phthalocyanines. Photochem. Photobiol. 42, 192-193.

Brasseur, N., H. Ali, D. Autenrieth, R. Langlois and J. E. van Lier (1985) Biological activities of phthalocyanines-III. Photoinactivation of V-79 Chinese hamster cells by tetrasulfophthalocyanines. Photochem. Photobiol. 42, 515-521.

Brasseur, N., H. Ali, R. Langlois and J. E. van Lier (1987) Biological activities of phthalocyanines-VII. Photoinactivation of V-79 Chinese hamster cells by selectively sulfonated phthalocyanines. Photochem. Photobiol. 45, 587-594.

Chan, W. S., R. Svensen, D. Phillips and I. R. Hart (1986) 
Cell uptake, distribution and response to aluminum chloro sulphonated phthalocyanine, a potential antitumour photosensitizer. Br. J. Cancer 53, 255-263.

Chatelier, R. C., W. H. Sawyer, A. G. Swincer and A. D. Ward (1985) Methods in Porphyrin Photosensitization (Edited by D. Kessel), p. 169. Plenum Press, New York.

Dougherty, T. J., G. Lawrence, J. E. Kaufman, D. G. Boyle, K. R. Weishaupt and A. Mittelman (1978) Photoradiation therapy for the treatment of malignant tumors. Cancer Res. 36, 2628-2635.

Fingar, V. H. and B. W. Henderson (1987) Drug and light dose dependence of photodynamic therapy: a study of tumor and normal tissue response. Photochem. Photobiol. 46, 837-841.

Girotti, A. W. (1983) Mechanism of photosensitization. Photochem. Photobiol. 38, 745-751.

Henderson, B. W. and D. A. Bellnier (1989) Tissue localization of photosensitizers and the mechanism of photodynamic tissue destruction. In Photosensitizing Compounds: Their Chemistry, Biology and Clinical Use (Edited by G. Bock and S. Harnett), Ciba Foundation Symposium 146, pp. 112-125. Wiley, Chichester.

Kessel, D. (1986) Sites of photosensitization by derivatives of hematoporphyrin. Photochem. Photobiol. 44, $489-493$.

Kessel, D., P. Thompson, K. Saatio and K. D. Nantwi (1987) Tumor localization and photosensitization by sulfonated derivatives of tetraphenylporphine. Photochem. Photobiol. 45, 787-790.

Langlois, R., H. Ali, N. Brasseur, R. Wagner and J. E. van Lier (1986) Biological activities of phthalocyanines-IV. Type II sensitized photooxidation of L-tryptophan and cholesterol by sulfonated metallophthalocyanine. Photochem. Photobiol. 44, 117-125.

Lier, J. E. van (1990) Phythalocyanines as sensitizers for PDT of cancer. In Photodynamic Therapy of Neoplastic Disease (Edited by D. Kessel), Vol. I, pp. 279-291. CRC Press, Boca Raton, FL.

Lier, J. E. van and J. D. Spikes (1989) The chemistry, photophysics and photosensitizing properties of phthalocyanines. In Photosensitizing Compounds: Their Chemistry, Biology and Clinical Use (Edited by G. Bock and S. Harnett), Ciba Foundation Symposium, 146, pp. 17-26. Wiley, Chichester.
Moan, J., T. Christensen and P. B. Jacobsen (1984) Photodynamic effects on cells in vitro labelled with hematoporphyrin derivative. Photobiochem. Photobiophys. 7, 349-358.

Moan, J., J. McGhie and P. B. Jacobson (1983) Photodynamic effects on cells in vitro exposed to hematoporphyrin derivative and light. Photochem. Photobiol. 37, 599-604.

Paquette, B., H. Ali, R. Langlois and J. E. van Lier (1988) Biological activities of phthalocyanines-VIII. Cellular distribution in V-79 Chinese hamster cells and phototoxicity of selectively sulfonated aluminum phthalocyanines. Photochem. Photobiol. 47, 215-220.

Paquette, B., H. Ali, R. Langlois and J. E. van Lier (1990) Biological activities of phthalocyanines-XI. Phototoxicity of sulfonated aluminum naphthalocyanines towards V-79 Chinese hamster cells. Photochem. Photobiol. 51, 313-318.

Redmond, R. W. and S. E. Braslavaky (1988) Photosensitization. Molecular, Cellular and Medical Aspects (Edited by G. Moreno, R. H. Pottier and T. G. Truscott), Nato ASI Series, Vol. H15, pp. 93-97. Springer, Berlin.

Reed, M. W. R., T. J. Wieman, D. A. Schuschke, M. T. Tseng and F. N. Miller (1989) A comparison of the effects of photodynamic therapy on normal and tumor blood vessels in the rat microcirculation. Radiation Res. 119, 542-552.

Rodgers, M. A. J. and P. T. Snowden (1982) Lifetime of $\mathrm{O}_{2}\left({ }^{1} \Delta_{\mathrm{g}}\right)$ in liquid water as determined by time-resolved infrared luminescence measurements. J. Am. Chem. Soc. 104, 5541-5543.

Rosenthal, I. and E. Ben-Hur (1989) Phthalocyanines in photobiology. In Phthalocyanines, Properties and Applications (Edited by C. C. Leznoff and A. B. P. Lever), pp. 393-425. VCH, New York.

Selman, S. H., M. Kreimer-Birnbaum, J. E. Klaunig, P. J. Goldblatt, R. W. Keck and S. L. Britton (1985) Blood flow in transplantable tumors treated with hematoporphyrin derivative and light. Cancer Res. 45, 1924-1927.

Star, W. M., H. P. A. Marunissen, A. E. van den Berg Blok, J. A. C. Versteeg, K. A. P. Franken and H. S. . Reinhold (1986) Destruction of rat mammary tumor and normal tissue microcirculation by hematoporphyrin derivative photoradiation observed in vivo in sandwich observation chambers. Cancer Res. 46, 2532-2540. 
